\title{
Influence of Cross-sectional Area Ratio between Shaft and Tunnel and Heat Release Rate on the Plug-holing Phenomenon in Natural Ventilated Tunnel fire
}

\author{
Kibea Hong ${ }^{1}$, Junyoung $\mathrm{Na}^{2}$, Hong Sun Ryou ${ }^{2}$ \\ ${ }^{1}$ Department of Automotive Engineering, Korea National University of Transportation \\ 50, Daehak-ro, Daesowon-myeon, Chungju-si, Republic of Korea \\ gbhong56@naver.com; \\ ${ }^{2}$ Department of Mechanical System Engineering, Chung-Ang University \\ 84, Heukseok-ro, Dongjak-gu, Seoul, Republic of Korea \\ junyoung628@naver.com; cfdmec@cau.ac.kr
}

\begin{abstract}
Suppression of plug-holing phenomenon is important in tunnel design. Experimental analysis of the influence of crosssectional area ratio of tunnel and vertical shaft and heat release rate on plug-holing phenomenon in natural ventilation system. In the experiment model reduced to 1/20 size, the aspect ratio of the tunnel and vertical axis was fixed and the effect of plug-holing phenomenon was confirmed by changing the cross - sectional area ratio between tunnel and vertical shaft. Experimental results show that the plugholing phenomenon is caused by the comparison of the smoke layer interface temperature and the temperature in the vertical shaft, and that the flow and temperature distribution under the vertical shaft changes with increasing cross-sectional area ratio of the tunnel and vertical vents. The plug-holing phenomenon is affected by the cross-sectional area ratio of the tunnel and vertical shaft. The larger the cross-sectional area ratio, the greater the possibility of plug-holing.
\end{abstract}

Keywords: Plug-Holing Phenomenon, Area Ratio, Natural Ventilation System, Shallow Underground Tunnel.

\section{Introduction}

The construction of tunnels is increasing due to the resolution of traffic problems caused by the high density of the world cities. In recent years, construction of shallow underground tunnels has been increasing to reduce cost and construction time. In this shallow underground tunnel, natural exhaust system is mainly used. Plug-holing is a phenomenon that when the smoke is discharged from the tunnel to the natural exhaust, fresh air at the bottom of the smoke layer is discharged together with the smoke by buoyancy, and the discharge flow rate of the smoke is lower than the design flow rate. This phenomenon must be taken into account when designing tunnels. Numerous studies have been conducted to suppress plug-holing phenomenon. Hinkley first defined the plug-holing phenomenon in the natural ventilation system in the tunnel and proposed Modified Froude number as a criterion. However, there was no shaft that caused the stack effect, and there was a limit that did not consider the influence of the shape of tunnel and shaft[1]. Spratt studied how the size, shape, and position of vertical shaft affect the plug-holing phenomenon through experiments. Spratt's experiments are not suitable for natural ventilation systems because of the use of axial fans[2]. After that, Ji studied the relation between the heat release rate of the pool fire, the height of the vertical shaft and the plug-holing phenomenon through the real scale model, and proposed a modified Richardson number as a new criterion[3]. The geometrical characteristics of tunnels and vertical shafts are important factors in ventilation systems in tunnels. As seen in previous studies, the plug-holing phenomenon of natural ventilation systems affects the size of the heat release rate and the geometrical characteristics of the tunnel and vertical shafts. In order to suppress the occurrence of plug-holing phenomenon, the geometrical characteristics of the tunnel and the natural ventilation must be considered together. In this study, the influence of the cross-sectional area ratio of the tunnel and vertical shaft on the plug-holing phenomenon is analysed. 


\section{Plug-holing phenomenon \\ 2.1. Definition of Plug-holing}

When a fire occurs in the Shallow underground tunnel, smoke and heat flow from the fire source and rise. After that, they can no longer rise to the ceiling and spread along the ceiling, which is called ceiling jet flow[4]. The smoke moving along the ceiling is exhaust through smoke by the stack effect on the vertical shaft. The smoke moving along the ceiling is exhaust through smoke by the stack effect on the vertical shaft. Because the flow direction of the ceiling jet flow changes from horizontal to vertical, a momentum change occurs below the vertical shaft. Due to the change in momentum, fresh air penetrates and mixes with the smoke layer below the vertical shaft, which is called the Sunken area [6-7]. When this sunken area rises to the inside of the shaft, fresh air is discharged from the shaft and this fresh air reduces smoke emissions. With the plug-holing phenomenon, the smoke exhaust rate does not satisfy the designed smoke exhaust rate. In a real tunnel, the smoke motion below the vertical ventilation is difficult to observe and measure, so the occurrence of the plug-holing phenomenon is not clear.

\subsection{Determination of plug-holing}

Plug-holing means that the Sunken area with fresh air and smoke enters into the vertical vent. However, this sunken area is difficult to define in height because it is a mixture of fresh air and smoke[5]. In this case, it can be determined using the smoke layer interface temperature. The reliability of the smoke layer interface temperature is low because the $\mathrm{N}$-percentage rule used at the beginning of the plug-holing study is changed by the selected arbitrary value N[6]. Precise definition is needed to improve the reliability of the Smoke layer interface temperature. Jannsens proposed a model to calculate the height of the smoke layer using the transverse temperature distribution in the tunnel. In this study, Jannsens' model was used. The calculated smoke layer height is calculated by substituting the vertical temperature distribution in the tunnel used for the calculation to calculate the smoke layer interface temperature[7].

\section{Experimental Method}

\subsection{Experimental model}

There are many limitations in performing actual tunnel fire tests. In most studies, numerical analysis or reduced model experiments are performed. Froude similarity law(Eqs. (1)), which has been validated for tunnel fire phenomena research, was applied to construct a reduced model[9-12].

$$
Q_{M}=Q_{F}\left(\frac{l_{M}}{l_{F}}\right)^{5 / 2}
$$

The tunnel used in the experiment is a real tunnel (length $140 \mathrm{~m}$, height $6 \mathrm{~m}$, width $8.4 \mathrm{~m}$ ) reduced to 1:20. The schematic diagram of the reduced model tunnel is shown in Fig. 1. The reduced model is $7 \mathrm{~m}$ long, $0.3 \mathrm{~m}$ high, and 0.42 $\mathrm{m}$ wide. In order to change the area ratio (Fig. 1) of the tunnel and vertical shaft, the shape of the tunnel was fixed and the cross-sectional area of the vertical shaft was changed. The cross - sectional area ratio of tunnel to vertical shaft is $0.054,0.071,0.09,0.11$. The vertical shaft is located $2.3 \mathrm{~m}$ from the source of the fire. The height of the vertical shaft also affects the smoke flow and plug-holing phenomenon. The critical shaft height and the depth of the shallow under ground were applied to fix the vertical shaft height to $0.15 \mathrm{~m}[9]$. The outer wall of the tunnel and vertical shaft is made of $0.08 \mathrm{~m}$ thick acrylic. The space near the pool fire is composed of steel and fireproof board to prevent deformation due to heat. In order to simulate a fire in a tunnel, a square pool of $0.025,0.035$, and $0.045 \mathrm{~m}$ in edge length was used[12]. N-heptane (purity: 99\%) was used as fuel for the fire. The mean value of quasi - steady - state zone of pool fire was used as representative value of experiment. In addition, the quasi - steady - state region varies with the size of the pool fire. Table 1 shows burning, heat release rate and heat release rate in actual fire according to the steady-state selection time and pool area. In this experiment, the maximum heat release rate of $2.99 \mathrm{MW}$ for the largest full-area 20.25 fire is similar to the maximum heat release rate for a $2000 \mathrm{cc}$ passenger car fire without fuel. The smaller pool area simulates the growth period of passenger car fire. 


\subsection{Experiment configuration}

The temperature distribution was measured from two thermocouple trees to determine the calculation of the smoke layer interface temperature and the occurrence of the plug-holing phenomenon in the vertical shaft. The transverse direction thermocouple tree of the tunnel was installed at a distance of $2 \mathrm{~m}$ from the source of the fire, because it should be installed far to the fire source without the influence of the plug-holing occurring below the vertical shaft. This thermocouple tree is used to estimate the smoke layer interface temperature. The transverse direction thermocouple tree of the tunnel consists of 15 thermocouples spaced $0.02 \mathrm{~m}$ apart to measure the vertical temperature distribution. In addition, to determine the inflow of fresh air into the vertical shaft, a thermocouple tree was installed at the inlet of the vertical shaft in the longitudinal direction of the tunnel at intervals of $0.01 \mathrm{~m}$ according to the sectional area ratio. The thermocouple used in the experiment is $\mathrm{K}$-type (Chromel-alumel, temperature range: $-200 \sim 1250{ }^{\circ} \mathrm{C}$, error rate: $1.1^{\circ} \mathrm{C}$ or $0.4 \%$ ). In addition, a laser sheet generator (LW-9117) was installed to visualize the smoke flow. The schematic diagram of the experiment is shown in Fig. 2 .

Table 1: Combustion characteristics according to different pool areas.

\begin{tabular}{r|r|r|r|r}
\hline \multicolumn{1}{l|}{ Pool area $\left[\mathrm{cm}^{2}\right]$} & Quasisteady statet timeregion [sec] & Mass bumingrate $[\mathrm{g} / \mathrm{s}]$ & CalculatedHRR $[\mathrm{kW}]$ & Real scaleHRR[MW] \\
\hline \hline 6.25 & $300 \sim 400$ & 0.0124 & 0.55 & 0.98 \\
\hline 12.25 & $450 \sim 550$ & 0.0220 & 0.98 & 1.75 \\
\hline 20.25 & $650 \sim 750$ & 0.0375 & 1.67 & 2.99 \\
\hline
\end{tabular}

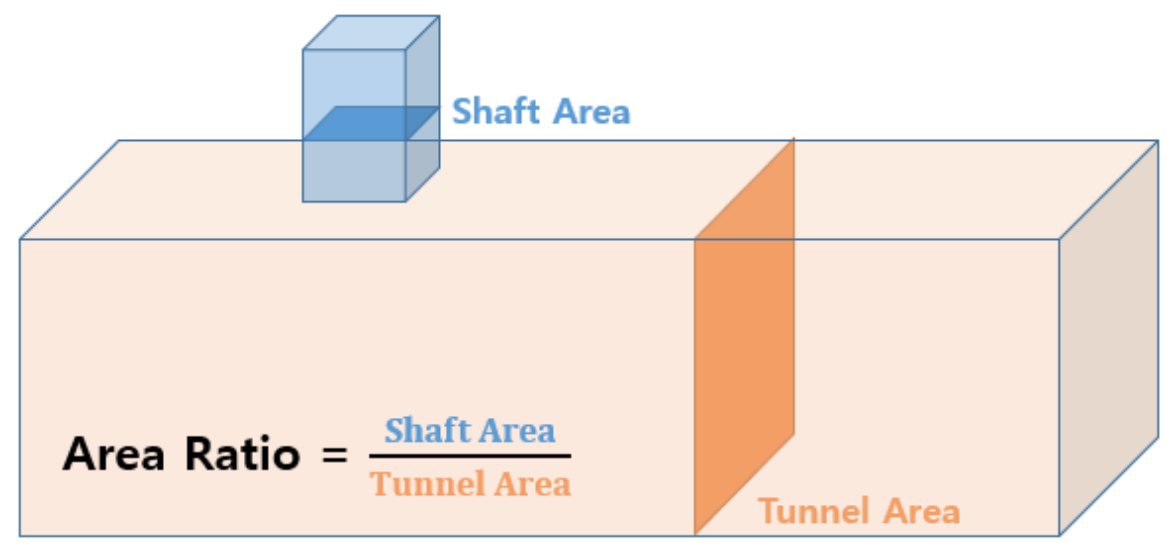

Fig. 1: Area ratio between tunnel and shaft. 


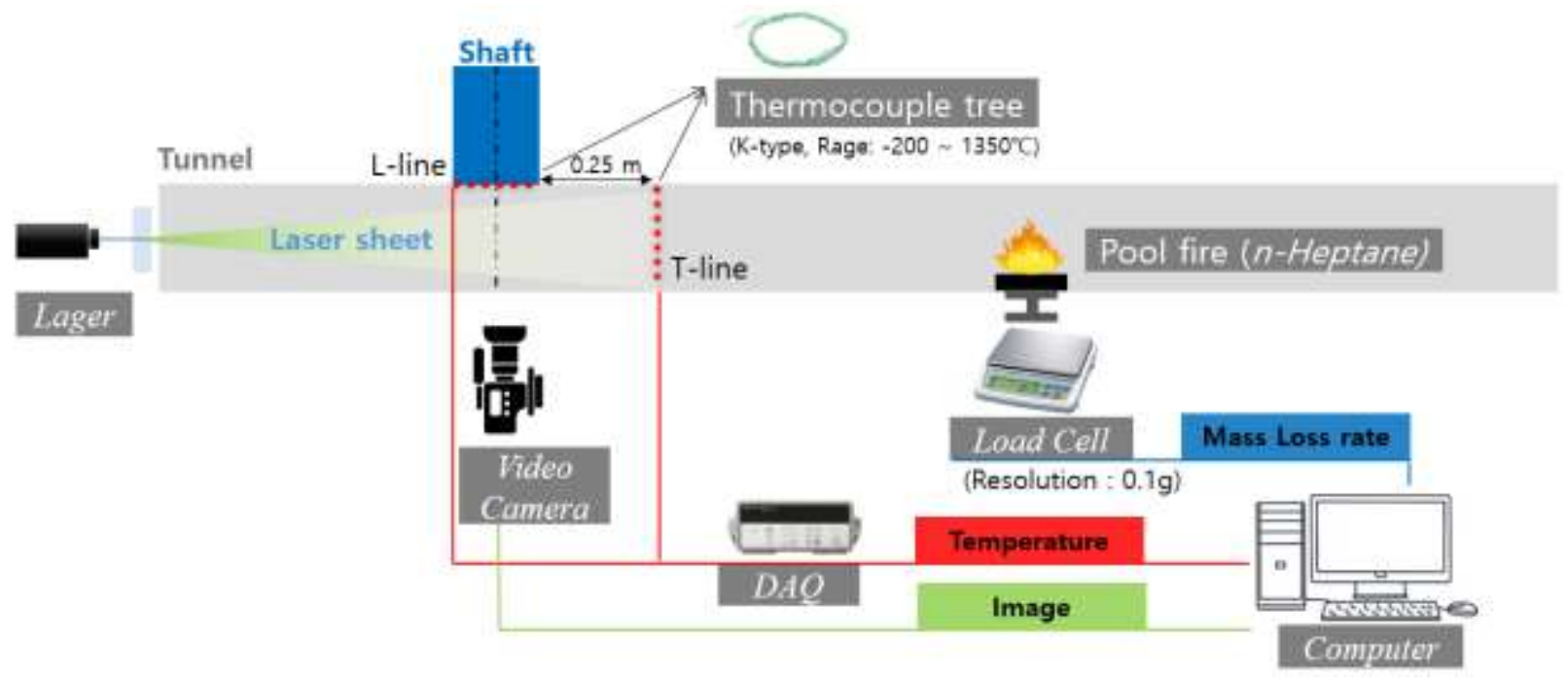

Fig. 2: The schematic of the reduced tunnel.

\section{Result and discussion}

This experiment was carried out to investigate the effect of cross-sectional area ratio of tunnel and vertical shaft and heat release rate on plug-holing phenomenon. In order to analyze the plug-holing phenomenon, a thermocouple tree in the transverse direction of the tunnel was installed to calculate the smoke layer interface temperature. Changes in the vertical shaft cross-sectional area will result in changes in the buoyancy and inertia forces of the smoke below the vertical shaft, which will affect plug-holing phenomenon. We checked the plug-holing phenomenon by using the temperature obtained from the thermocouple tree installed in the vertical shaft.

\subsection{Transverse temperature distribution in tunnel}

Fig. 3 shows the temperature distribution graph obtained from the transverse direction thermocouple tree installed $0.25 \mathrm{~m}$ from the vertical shaft in the tunnel. Fig. 3 is a graph of transverse direction temperature distribution according to the cross-sectional area ratio. It shows the highest temperature rise from $0.2 \mathrm{~m}$ and the highest smoke temperature at $0.28 \mathrm{~m}$. This tendency was the same in all pool areas. In addition, the transverse direction temperature of Table 2 shows that the temperature increases as the cross-sectional area ratio decreases. This showed the same trend in all pool fires. This is because the vertical shaft sectional area becomes smaller and the air leaving the vertical shaft becomes relatively small.

\subsection{Temperature distribution in longitudinal direction of tunnel in shaft}

Fig. 4 shows the longitudinal direction temperature distribution of the tunnel obtained from the thermocouple installed at $0.01 \mathrm{~m}$ distance between the tunnel and the vertical shaft. In Table 2, the average temperature inside the vertical shaft increases with decreasing cross-sectional area ratio. This is because the sectional area of the vertical shaft becomes smaller and the air discharged from the vertical shaft becomes smaller. In the vertical shaft, the longitudinal direction temperature distribution of the tunnel is normalized because the vertical shaft depth is different for each crosssectional area ratio. The highest temperature was measured at around 0.25 relative to the depth of the normalized vertical shaft. This is the portion where the smoke of the ceiling jet flow is ejected from the vertical shaft directly to the $0.02 \mathrm{~m}$ distance from the entrance of the vertical vent. The same tendency is seen in each pool fire. Also, as the sectional area ratio of the tunnel and vertical shaft increases, the difference between the maximum temperature and the minimum temperature in the vertical shaft also increases. As the cross-sectional area ratio increases, the air flow into the vertical shaft increases and the temperature inside the vertical shaft decreases. 


\subsection{Judgement of plug-holing occurrence}

When the smoke layer interface temperature is compared with the minimum temperature at the inside of the vertical shaft, and the internal temperature of the vertical shaft is lower than the smoke layer interface temperature, fresh air beneath the vertical shaft is discharged together with the smoke. It is determined that plug-holing has occurred. The smoke layer interface temperature is obtained from the transverse direction temperature distribution in the tunnel using Janssens's model [9]. As a result of plug-holing judgment, Plug-holing phenomenon through flow visualization did not occur at cross-sectional area ratio of 0.054 and 0.071 , and occurred at cross-sectional area ratio of 0.09 and 0.11 . Table 2 summarizes heat release rate, plug-holing occurrence, smoke layer interface temperature, and minimum temperature in vertical shaft. If $\Delta \mathrm{T}$ is the difference between the smoke boundary layer temperature and the minimum temperature in the vertical shaft, a negative value indicates that there is no fresh air in the vertical shaft. This means that no plug-holing has occurred. On the contrary, if the value is positive, it can be considered that fresh air inflow is lower than the smoke layer interface temperature in the vertical shaft, and it is judged that plug-holing occurs in this case. The higher the cross-sectional area ratio of the tunnel and vertical shaft at the fixed heat release rate, the higher the value of the minimum temperature in the vertical shaft than the smoke layer interface temperature and the greater the possibility of plug-holing.

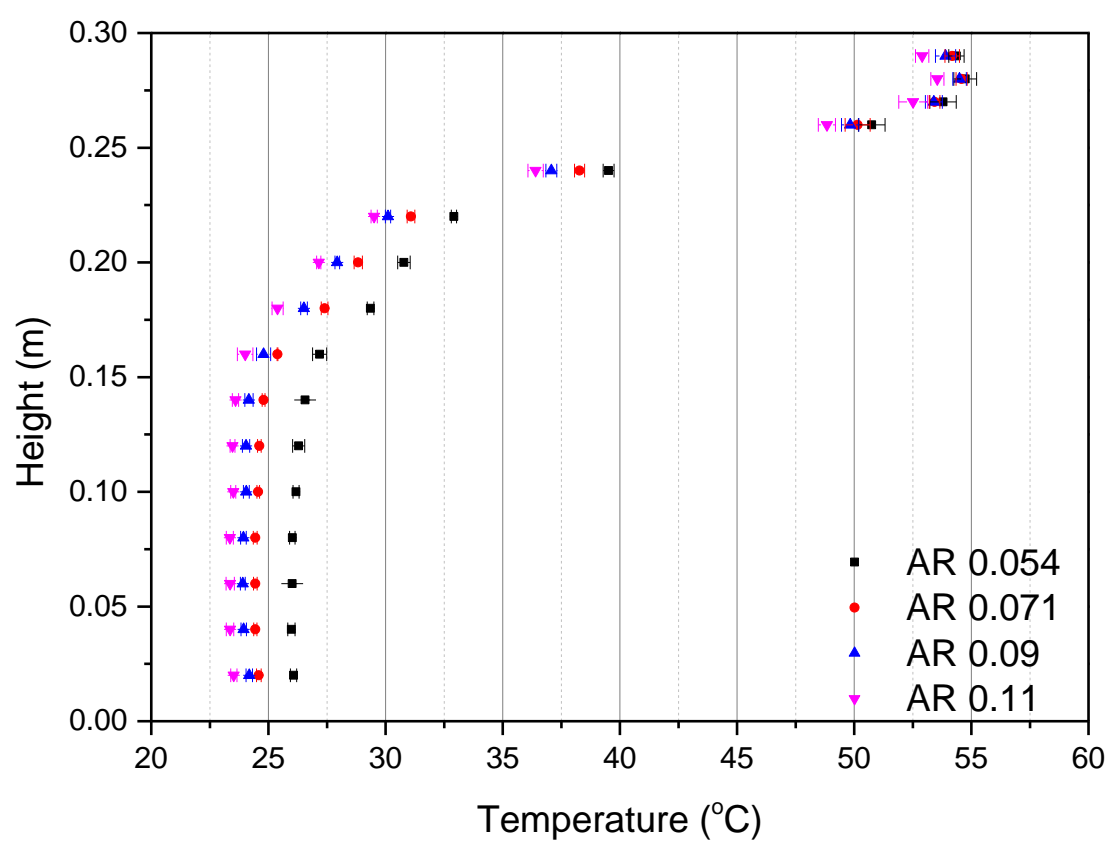

Fig. 3: Transverse temperature distribution in tunnel(Pool area $\left.20.25 \mathrm{~cm}^{2}\right)$. 


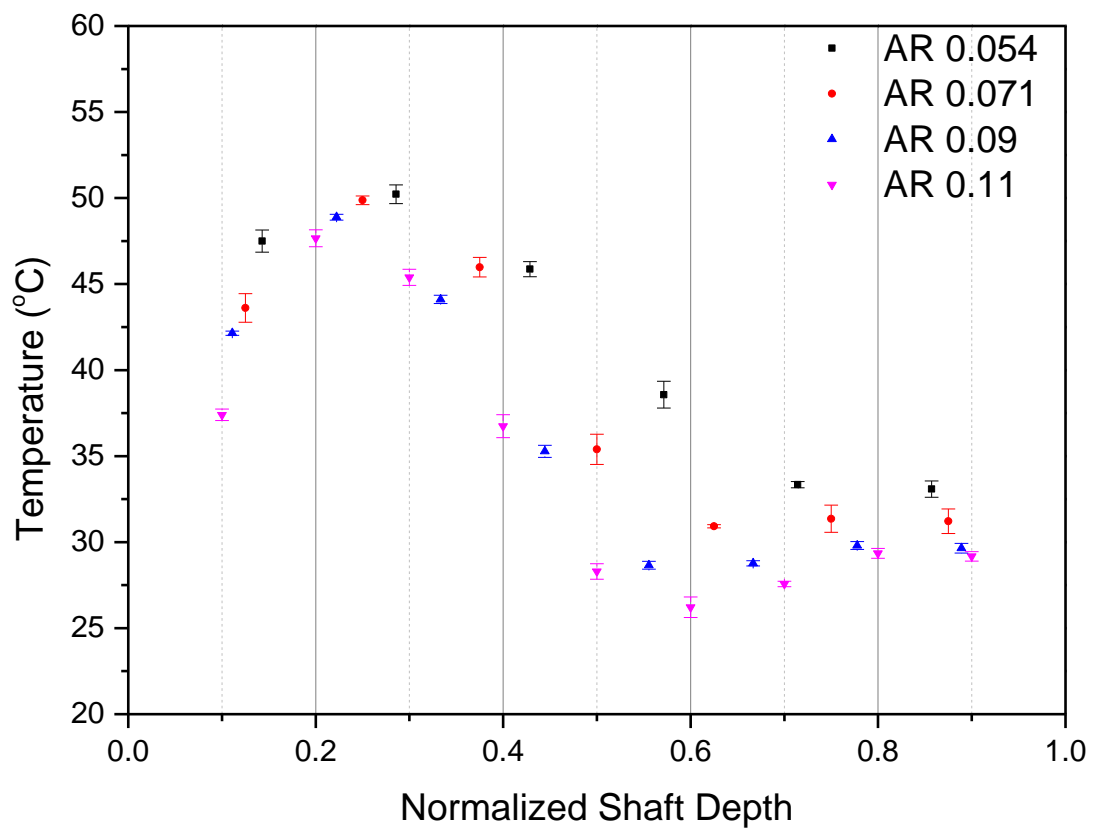

Fig. 4: Longitudinal temperature distribution in vertical shaft(Pool area $\left.20.25 \mathrm{~cm}^{2}\right)$. 
Table 2: The judgment of plug-holing in all case.

\begin{tabular}{|c|c|c|c|c|c|c|c|}
\hline $\begin{array}{l}\text { HRR } \\
{[\mathrm{kW}]}\end{array}$ & $\begin{array}{c}\text { Area } \\
\text { ratio } \\
{[-]}\end{array}$ & $\begin{array}{c}\text { Occurrence } \\
\text { of Plug- } \\
\text { holing }\end{array}$ & $\begin{array}{l}\text { Averaged } \\
\text { temperature in } \\
\text { transverse } \\
\text { direction } \\
\text { (Tunnel) }\end{array}$ & \begin{tabular}{|l|} 
Averaged \\
temperature \\
longitudinal \\
direction (shaft)
\end{tabular} & $\begin{array}{c}\text { Temperature of } \\
\text { smoke layer } \\
\text { interface, } T_{\text {int }}\left[{ }^{\circ} \mathrm{C}\right]\end{array}$ & $\begin{array}{c}\text { Minimum } \\
\text { temperature } \\
\text { in shaft, } T_{\text {shaft }} \\
{\left[{ }^{\circ} \mathrm{C}\right]}\end{array}$ & $\Delta \mathrm{T}=T_{\text {int- }} T_{\text {shaft }}$ \\
\hline \multirow{4}{*}{0.55} & 0.054 & $X$ & 28.65 & 31.76 & 27.06 & 29.60 & -2.54 \\
\hline & 0.071 & $X$ & 27.99 & 30.28 & 26.80 & 27.68 & -0.88 \\
\hline & 0.090 & $\mathrm{O}$ & 27.85 & 29.78 & 26.76 & 26.53 & 0.23 \\
\hline & 0.110 & $\mathrm{O}$ & 27.79 & 29.08 & 26.71 & 26.15 & 0.56 \\
\hline \multirow{4}{*}{0.98} & 0.054 & $X$ & 31.05 & 36.35 & 29.05 & 30.10 & -1.05 \\
\hline & 0.071 & $X$ & 30.62 & 35.35 & 28.67 & 28.82 & -0.15 \\
\hline & 0.090 & $\mathrm{O}$ & 30.43 & 33.70 & 28.63 & 27.58 & 0.67 \\
\hline & 0.110 & $\mathrm{O}$ & 30.20 & 32.64 & 28.27 & 27.30 & 0.96 \\
\hline \multirow{4}{*}{1.67} & 0.054 & X & 34.78 & 41.43 & 31.70 & 33.08 & -1.38 \\
\hline & 0.071 & $X$ & 33.45 & 38.33 & 30.50 & 30.92 & -0.42 \\
\hline & 0.090 & $\mathrm{O}$ & 32.89 & 35.91 & 30.49 & 28.65 & 1.84 \\
\hline & 0.110 & $\mathrm{O}$ & 32.15 & 34.20 & 29.45 & 26.22 & 3.23 \\
\hline
\end{tabular}

\section{Conclusion}

In this study, we investigated the effect of cross-sectional area ratio and heat release rate between tunnel and vertical shaft on plug-holing phenomenon in tunnel fire. Based on the temperature distribution, the heat release rate of less than $3 \mathrm{MW}$ and the aspect ratio of the tunnel and the vertical vent are fixed and analyzed to obtain the following conclusions.

1. As the cross-sectional area ratio of the tunnel to the vertical shaft increases, the flow and temperature distribution characteristics under the vertical shaft change.

2. Plug-holing is affected by the cross-sectional area ratio of the tunnel and vertical ventilation. The larger the crosssectional area ratio, the greater the possibility of plug-holing.

3. The change in the heat release rate affects the smoke layer interface temperature, the temperature distribution inside the vertical shaft and the smoke flow, but it does not affect the occurrence of plug-holing.

4. The cross-sectional area ratio of the tunnel and vertical shaft has a direct effect on the occurrence of plug-holing phenomenon, so it is important to consider the cross-sectional area ratio when designing the tunnel. 


\section{Acknowledgements}

The research was supported by a grant from the Academic Research Program of Korea National University of Transportation in 2019 and Research and Development to Enhance Firefighting Response Ability founded by National Fire Agency(“2018-NFA002-007-01010002-2018”).

\section{References}

[1] P. L. Hinkley, "The flow of hot gases along an enclosed shopping mall a tentative theory," Fire Safety Science 807, FIRE research station, UK, pp.5-15.

[2] D. Spratt, A. Heselden, "Efficient extraction of smoke from a thin layer under a ceiling," Fire Safety Science 1001, Fire Safety Science, FIRE research station, UK, pp.5-11.

[3] J. Ji, Z.H. Gao, C.G. Fan, W. Zhong, J.H. Sun, "A study of the effect of plug-holing and boundary layer separation on natural ventilation with vertical shaft in urban road Tunnel fires," International Journal of Heat and Mass Transfer, vol. 55, no. 21-22, pp.6032-6041, 2012.

[4] Morgan J. Hurley, SFPE handbook of fire protection engineering. Springer, pp. 429-454, 2015.

[5] J. Ji, Z.H. Gao, J.H. Sun, "Large Eddy Simulation of stack effect on natural smoke exhausting effect in urban road Tunnel fires," International Journal of Heat and Mass Transfer, vol. 66, pp. 531-542, 2013.

[6] L. Y. Cooper, M. Harkleroad, J. Quintiere, W. Rinkinen, "An Experimental Study of Upper Hot layer Stratification in Full-Scale Multiroom Fire Scenarios," J. Heat Transfer, 1982.

[7] M. Janssens, H. C. Tran, "Data Reduction of Room Tests for Zone Model Validation," J. Fire Sci., vol. 10, pp. 528$555,1992$.

[8] S. Zhang, K. He, Y. Yao, M. Peng, H. Yang, J. Wang, X. Cheng, "Investigation on the critical shaft height of plugholing in the natural ventilated tunnel fire," International Journal of Thermal Sciences, vol. 132, pp. 517-533, 2018.

[9] J. G. Quintiere, "Scaling applications in fire research," Fire Safety Journal, vol. 15, no. 1, pp. 3-29, 1989

[10] F. Mei, F. Tang, X. Ling, J. Yu, "Evolution characteristics of fire smoke layer thickness in a mechanical ventilation tunnel with multiple point extraction," Applied Thermal Engineering, vol. 111, pp. 248-256, 2017.

[11] C. G. Fan, J. Ji, Z. H. Gao, J. Y. Han, J. H. Sun, "Experimental study of air entrainment mode with natural ventilation using shafts in road tunnel fires," International Journal of Heat and Mass Transfer, vol. 56, no. 1-2, pp. 750-757, 2013.

[12] A. Hamins, T. Kashiwagi, R. R. Buch, "Characteristics of Pool Fire Burning," Fire Resistance of Industrial Fluids, American Resistance of Industrial Fluids, IN, pp.19-24. 